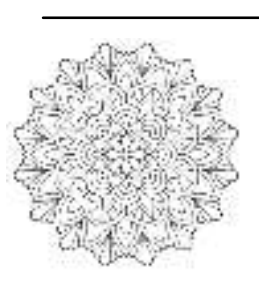

AL HIKMAH: INDONESIAN JOURNAL OF EARLY CHILDHOOD ISLAMIC EDUCATION

ISSN (P): 2550-2200, ISSN (E): 2550-1100,

VOL. 4 (2), 2020, PP.154 - 170

http://journal.iaialhikmahtuban.ac.id/index.php/ijecie

\title{
MENINGKATKAN KEPERCAYAAN DIRI ANAK DENGAN MEMBEDAH NILAI- NILAI YANG TERKANDUNG PADA DONGENG CINDELARAS
}

\author{
M Munawwir Shofiyulloh ${ }^{1}$, Abdul Muhid ${ }^{2}$ \\ ${ }^{1}$ Universitas Islam Negeri Sunan Ampel Surabaya \\ ${ }^{2}$ Universitas Islam Negeri Sunan Ampel Surabaya
}

unashofii@gmail.com

Abstrak

Percaya diri akan budayanya, percaya diri akan pribadi bangsanya, percaya diri akan nilai luhur yang seharusnya telah mendarah daging dalam sanubari merupakan proses penanaman yang baik utuk menjaga kelestarian dari peradaban dari suatu bangsa. Dengan era globalisasi yang kian liberal mewajibkan penggalakan mengenai nilai-nilai pada kearifan lokal. Salah satu produk hasil dari kebudayaan lokal tersebut adalah dongeng rakyat asal Jawa Timur yaitu Cindelaras. Tujuan dari penelitian ini adalah mencari pesan-pesan yang terkandung darisuatu dongeng atau cerita rakyat Cindelaras ini untuk meningkatkan kepercayaan diri seorang anak dan menghidupkan kembali cerita-cerita lama agar budaya-budaya Indonesia dalam apapun bentuknya, tidak tergerus dengan budaya-budaya asing lainnya. Hasil temuan setelah dilakukannya penelitian akan tema di atas menunjukkan bahwa dengan membacakan dongeng kepada anak dapat meningkatkan rasa percaya diri mereka, hal ini dikarenakan terdapat nilai-nilai yang bisa diambil dari setiap dongeng tersebut. Apabila ditelaah satu persatu dari setiap kejadian dalam dongeng, anak akan lebih mengambil intisari darinya. Di sisi lain ini merupakan langkah untuk menjaga dari tradisi dan budaya lokal.

Kata kunci: Percaya Diri, Dongeng Rakyat, Cindelaras
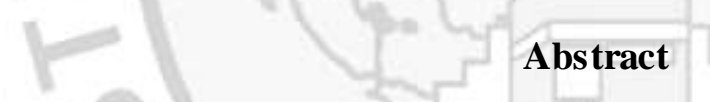

Confidence in the culture, confidence in the private nation, confidence in the noble values that have been agreed ingrained in the heart is a good planting process used to save from the civilization of several nations. With the increasingly liberal era of globalization requires merging of values in local wisdom. One of the products of this local culture is the folklore from East Java, Cindelaras. The purpose of this study is to find the messages contained in fairy tales or folklore Cindelaras to increase children's confidence and revive old stories so that Indonesian cultures in any form, not eroded by other cultures. The results of the study after studying the research will discuss about what makes reading fairy tales to children increases their confidence, this is related to the values that can be taken from each of these tales. If examined one by one from each incident in a fairy tale, children will take more essence from it. On the other hand this is a step to involve local traditions and culture.

Keyword: Self-Confidence, Folklore, Cindelaras 
PENDAHULUAN

Globalisasi adalah kabar baik, tetapi di sisi lain juga merupakan kabar buruk. Masalah yang paling krusial atau penting dalam globalisasi, yaitu kenyataan bahwa dengan perkembangan ilmu pengertahuan dan teknologi dikuasai oleh negara-negara maju. Ini berdampak mengakibatkan negara-negara berkembang takut tertinggal dalam arus deras globalisai yang kian membabi buta. Baik itu dalam berbagai bidang seperti pendidikan, religius, politik, ekonomi, sosial, budaya, ataupuntermasuk kesenian Indonesia (Suneki, 2012: 313),

Dampak positif dari globalisasi adalah terjadinya perubahan tatanan nilai dan sikap, berkembangnya IPTEK, menuju tingkat kehidupan yang lebih baik. Sedangkan dampak negatif dari globalisasi adalah, pola hidup konsumtif, sikap individualistik, gaya hidup kebarat-baratan serta kesenjangan sosial (Nurhaidah dan Musa, 2015: 1).

Dilansir dari kompasiana dengan judul hilangnya budaya indonesia memang tidak bisa dipungkiri bahwa dengan era globalisasi yang meningkatkan media transportasi, komunikasi, sumber daya, dan jaringan internet, serta peralatan teknologi lainnya. Dengan kecanggihan itu ternyata mengakibatkan perkembangan budaya indonesia kian merosot apalagi dengan generasi muda yang pasif mengikuti kegiatan-kegiatan kebudayaan serta tidak dijaminnya dari pemerintah akan pelestarian budaya yang ada (Saputra, 2018).

Pada era globalisasi juga terjadinya asimilasi, dengan tanpa adanya batas akses untuk melihat bagian dunia yang lain. Maka dengan bantuan internet, semua orang akan dipertemukan nilai-nilai dari suatu budaya yang baru dan tanpa adanya filtrasi atau tanpa adanya banyak imbang dan menganggap budaya sendiri kuno maka indonesia sedikit demi sedikit akan kehilangan budayanya sendiri (Saputra, 2018). Asimilasi sendiri berarti penyesuaian atau peleburan sifat asli yang dimiliki dengan sifat lingkungan sekitar (Idrus, 2007: 52). Dampak asimilasi di Indonesia terlihat dari mode, riasan, gaya bahasa, kebiasaan, dan perilaku yang berubah dengan mengikuti trend dunia.

Hal yang paling ditakutkan, tetapi sudah menjadi hal yang maklum adalah sebuah bangsa yang mulai kehilangan akan identitas dan kepribadian (Suparno, 2010: 3). Cara memupuk kembali budaya indonesia yang mulai tergerus dengan cara memberikan memberikan generasi muda pemahaman akan cemerlangnya budayanya sendiri. Salah satu solusi dengan memberikan dongeng rakyat asli dari suatu daerah yang memiliki kekhasannya masing-masing. 
Dongeng merupakan salah satu bentuk folklor. Folklor meliputi legenda, musik, sejarah lisan, pepatah, lelucon, takhayul, dongeng, dan kebiasaan yang menjadi tradisi dalam suatu budaya, subkultur, atau kelompok. Folklor juga merupakan serangkaian praktik yang menjadi sarana penyebaran berbagai tradisi budaya. Folklor berkaitan erat dengan mitologi (https://id. wikipedia.org/wiki/Folklor).

Menurut James Danandjaja sebagai bapak folklor, menyebutkan bahwa dongeng berupa bagian kebudayaan suatu kolektif, yang tersebar dan diwariskan turun menurun (dari generasi), secara tradisional dalam versi yang berbeda, baik dalam bentuk lisan maupun contoh, yang disertai dengan gerak isyarat atau alat pembantu pengingat. Dongeng juga memiliki keragaman sastra daerah yang mendukung proses pembangunan jati diri dan budaya lokal. Dongeng merupakan cerita khayalan atau cerita yang tidak benar-benar terjadi, biasanya bersifat menghibur dan mengandung nilai pendidikan. Biasanya dongeng dibuat karena terinspirasi dari suatu peristiwa (Habsari, 2017: 24).

Jika ditanya mengenai lebih paham mana anak sekarang perbandingan antara cerita reog ponorogo dengan upin ipin series, tentulah dengan kompaknya menjawan upin ipin yang negara asalanya dari negeri jiran. Pemahaman tersirat dari pertanyaan tersebut dikarenakan akses paling mudah dijamah oleh seorang anak adalah televisi, dan yang ditampilkan pada pertelevisian adalah upin ipin. Dengan kata lain memberdayakan dongeng atau cerita rakyat yang memiliki kekhasannya sendiri di banyak wilayah di Indonesia memberikan sumbangsih mengenai pelestarian budaya itu sendiri.

Poin pertama yang ingin disampaikan adalah bahwa perlu adanya tindakan agar budaya Indonesia tidak kalah, apalagi hilang atau dicaplok negara lain (Jananti, 2014: 260). Dengan mengerti akan produk budaya, anak akan dikenalkan pada keaneka ragaman pernakpernik Indonesia. Tidak hanya diajak pada peninggalan-peninggalan sejarah (bangunan dan peralatan), mnegikuti pawai agustusan yang rata-rata mengusung tema budaya lokal, kursus kesenian, melihat pertunjukkan (contoh: wayang atau ludruk). Tetapi, salah satunya adanya pelestarian melalui dongeng-dongeng atau cerita rakyat (Azzah, 2016).

Dongeng merupakan cara berinteraksi seorang manusia dengan lingkungan sekitar, karena dapat mewakili memori masyarakat banyak. Dongeng digunakan juga dalam merangkum nilai-nilai kehidupan. Keberadaan dongeng adalah tradisi kuno yang telah ada semenjak ribuan tahun. Dengan pembawaan yang menarik dan disampaikan dengan gaya bahasa yang ramah, suatu dongeng akan bisa bertahan lama. Apalagi dongeng tersebut menyangkut nama suatu wilayah. Narasi dalam dongeng/cerita tradisional telah diwariskan 
dari generasi ke generasi melalui cerita rakyat, lagu, ritual, nyanyian dan bahkan artefak yang menjelaskan bagaimana budaya itu bisa terbentuk. Melalui dongeng/cerita rakyat bisa menjadi "akar" dan membantu dalam membangun sebuah identitas diri dan jati diri bangsa.

Poin kedua, dengan memahami maksud, arah dan tujuan dari dongeng tersebut sembari menggali nilai sastranya, bisa juga dijadikan sebagai landasan dalam memberikan nasehat kepada anak. Baik diambilkan nilai nilai moral individual, nilai moral sosial, dan nilai moral religi (Habsari, 2017: 25). Diantara nilai individual tersebut terdapat penanaman kepercayaan diri yang dibentuk dari proses pengkajian nilai moral, sambil menyinggung bahwa secara tidak langsung anak mampu merespons cerita tersebut. Upaya ini bertujuan agar anak tahu bahwa banyak nilai implisit dari cerita rakyat atau dongeng. Cindelaras dipilih sebab dalam Cindelaras memiliki karakter-karakter yang memungkinkan untuk diambil wejangan-wejangannya. Hingga nantinya bisa diambil sifat-sifat percaya diri yang bisa teladani dan dibahas lebih lanjut. Terakhir sebagai seorang pribumi Jawa Timur penulis ingin merasakan kembali cerita-cerita asli yang ada di Buni kelahirannya.

\section{PEMBAHASAN}

\section{Percaya diri pada anak}

Perlu adanya batasan mengenai apa yang definisi dari anak yang akan dibahas dalam paper ini. Anak yaitu kelompok manusia muda usia yang batasannya umurnya tidak selalu sama di berbagai negara. Di Indonesia sering dipakai batasan umur anak dari 0 sampai 21 tahun. Dengan demikian dalam kelompoknya anak akan dikelompokkan bayi, anak balita, dan anak usia sekolah. Dalam berbagai perbedaan penentuan batasan umur anak ini, umumnya disepakati bahwa masa anak merupakan masa yang dilalui oleh setiap orang untuk menjadi manusia dewasa. Masa anak ditandai oleh proses tumbuh kembang, yang meliputi aspek fisik biologis serta mental, emotional, dan Psychosocial.

Di antara kurun masa anak yang cukup panjang itu, masa balita merupakan masa dengan tingkat pertumbuhan dan perkembangan yang cepat serta peka dalam peletakan dasardasar kepribadian. Sebagai contoh anak usia satu setengah tahun umumnya mencapai tinggi 2 kali lipat, dan berat 4 kali lipat, dibandingkan dengan tinggi dan berat badannya waktu lahir. Anak usia 5-6 tahun umumnya telah mampu melakukan hampir semua jenis gerak yang dilakukan oleh orang dewasa. Pada masa-masa selanjutnya anak mengalami proses penajaman fungsi-fungsi mental, belajar dalam pengendalian emosi, dan pengembangan diri 
sebagai makhluk sosial. Pertumbuhan fisik yang cepat terjadi lagi pada masa pubertas, yang diikuti dengan kematangan organ-organ reproduksi.

Berbagai perubahan tersebut dan lingkungan akan ikut menentukan temperamen anak, yang pada waktunya akan mempengaruhi kepribadiannya. Dalam kemudahan usia dan kurangnya pengalaman meniti berbagai perubahan yang dihadapinya, anak memerlukan bimbingan orang tua. Sehingga bimbingan orang tua diperlukan untuk menuntun anak menjadi manusia dewasa yang sehat jasmani dan rohani, serta mempunyai keterampilan yang dibutuhkan untuk hidup dengan baik di lingkungannya (Setiawan dkk, 2004).

Menurut Aprianti Rosita Rahayu percaya diri adalah salah satu modal basic guna menjalani kehidupan dengan optimis dan menjadi faktor yang berpengaruh terhadap kesuksesan seseorang. Percaya diri berarti seseorang memiliki motivasi dan semangat yang tinggi (Rahayu, 2013: 63). Percaya diri harus berdasarkan dari (action) tindakan nyata, (activities) kegiatan riil ,dan (effort) usaha untuk berbenah dan belajar dari kesalahan bukan lari atau melepas tanggung jawab keadaan yang seharusnya dan bersifat pasif.

Willfson berpendapat bahwa anak yang percaya diri adalah anak yang mampu meimiliki senyum keindahan dan kebahagiaan, serta dapat bersyukur dengan apa yang dimiliki. Pada dasarnya anak yang masih kecil memiliki kepercayaan diri yang alami (nature), sehingga dalam menghadapi sesuatu yang mustahil dan gagal berulang kalipun, anak bisa tetap mencoba dan terus mencoba karena rasa keingintahuan yang besar. Maka bisa disimpulkan percaya diri adalah sifat, sikap, emotional, dan mental anak yang memandang segala hal dengan kacamata positif. Penilaian itu ada pada kepribadian maupun kepada lingkungan anak. Diantara ciri-ciri percaya diri anak yang rendah:

1. Ragu-ragu

2. Menutup diri atau pendiam

3. Sering meminta bantuan

4. Takut berinteraksi sosial

Masalah kepercayaan diri pada anak pak seharusnya menjadi perhatian khusus, dengan kepercayaan diri yang sesuai maka seorang anak dapat berkembang dan tumbuh dengan baik. Jika percayaan ciri melanda seorang anak ditakutkan akan menjadi di gangguan secara psikologi ketika dihadapkan kepada tantangan atau situasi yang baru (Khotimah dan Quwwatun, 2015).

\section{Dongeng (Cerita Rakyat)}


Dongeng merupakan cerita khayalan(fantasi) yang bersifat irrasional karena terkadang memiliki karakter-karakter benda mati atau binatang yang bisa menyerupai manusia. Seperti kisah kancil dan buaya. Hewan-hewan pada cerita ini memiliki keunikan karena bisa berbicara dan berpikir (Rahimsyah, 2013: 55). Jadi, cerita yang terdapat di dalam dongeng adalah cerita khayalan yang terkadang di luar akal sehat (Kusumo, 2006: 9). Carr Lemon (1991) dan Cannadine menyatakan dongeng adalah cerita dari suatu sejarah atau kejadian masa lampau (past human events) yang pernah terjadi dalam satu wilayah dan tidak memiliki dokumentasi resmi, karena sumber sejarah hanya berupa tradisi lisan (Cooper, 2014).

Dari banyaknya pendapat tentang dongeng, maka dapat ditariik kesimpulan bahwa dongeng adalah cerita fiktif (tidak nyata) yang digunakan sengai media hiburan dengan mengandung nilai-nilai moral (Ardini, 2012: 46). Dari beberapa dongeng yang ada di dunia, maka dapat dikategorikan menjadi tujuh macam, yaitu cerita pelipur lara, mitos, cerita lucu, sage, fabel, legenda, dan perumpamaan, antara lain:

1. Mitos, bentuk dongeng yang menceritakan hal-hal magis seperti cerita tentang dewa24 dewa, peri atau Tuhan:

2. Sage, cerita berdasarkan peritiwa sejarah dan khayalan atau rekaan (Idrus: 2007:522). contohnya adalah dongeng tentang kepahlawanan, peperangan, atau sihir. Contohnya, cerita Pati Gajah Mada.

3. Fabel, cerita pendek dongeng penggambaran watak manuia yang diibaratkan hewan (Idrus, 2007: 202). Biasanya bercerita tentang binatang yang dapat berbicara, berpikir, dan berperilaku seperti manusia. Contohnya, Si Kancil Mencuri Mentimun.

4. Legenda, ceriata rakyat berkaitan sejarah (Idrus: 2007, 406). Dongeng seperti ini biasanya menceritakan tentang sebuah peristiwa tentang asal-usul dari suatu benda atau tempat. Contohnya, asal usul Bnayuwangi.

5. Cerita jenaka, cerita yang dapat membangkitkan tawa karena memiliki sisi humor yang disertakan sebagai hiburan belaka. Contohnya, Kisah Abu Nawas membohongi raja.

6. Cerita pelipur lara, cerita ini biasanya berbentuk narasi deskriptif untuk untuk menghibur tamu dalam suatu acara atau kegiatan dan diceritakan oleh seorang storyteller.

7. Cerita perumpamaan, bentuk dongeng yang mengandung kiasan, contohnya adalah didaktik dari Haji Pelit (Habsari, 2017: 28). Cerita tersebut tumbuh dan berkembang di daerah dan dinamakan cerita lokal Dudung. (2015). 
Cerita-cerita di atas banyak yang bersifat fantasi dan mampu menghidupkan kembali imajinasi. cerita fantasi adalah cerita khayalan berdasarkan impian tentang sesuatu yang tidak nyata.(Idrus, 2007: 203), ilustrasi dari objek dan keadaan tertentu yangsulit diterima oleh akal pikiran, baik itu hal yang mungkin atau tidak mungkin terjadi. Cerita fantasi bisa terbentuk dari ide-ide kreatif seseorang yang mengaitkan sesuatu yang irrasional, karenanya cerita fantasi dinilai mampu memebentuk pikiran yang kreatif dan dikembangkan.

David McCleland pada tahun 1970-an sebagai seorang peneliti psikologi alam bawah sadar manusia, pernah melakukan penelitian dengan pelatihan peningkatan motivasi berprestasi. Pelatihan itu diperkenalkan di Indonesia melalui Departemen Tenaga Kerja. Hasil dari penelitian itu berupa konsep, bahwa membangkitkan jiwa enterpreneur para pekerja dalam mencapai kesuksesan adalah kewajiban, dan salah satu kunci sukses adalah dengan tingginya motivasi. Motivasi yang dibentuk adalah dari khayalan tercapainya segala keinginan dari pekerja tersebut. Pada salah satu sesi pelatihan tersebut para peserta dilatih untuk mengisi alam khayalnya dengan fantasi-fantasi dengan kreasi, inovasi, dan prestasi (Setiawan, 2004: 253). Hal tersebut berguna pada pengembangan dan pertumbuhan ekonomi.

Di sisi lain dongeng juga disebut dengan kisah, sebuah tutur yang melukiskan suatu proses terjadinya peristiwa secara panjang lebar, karangan yang menyajikan jalannya kejadian kejadian, lakon yang diwujudkan dalam suatu bentuk pertunjukan (Idrus, 2007: 140). Dongeng adalah kisah yang dituturkan atau ditulis yang biasanya hasil rekaan saja yang sifatnya sebagai hiburan dongeng juga bisa berupa cerita lama (Idrus, 2007: 179).

Dalam versi lainnya, dongeng berarti cerita tentang benda hidup atau benda mati yang dibuat-buat hingga benda tersebut seolah nyata dan ada walapun hanyalah khayalan. Karakter dari tokohnya dapat berupa apapun, asalkan bersifat seperti manusia. Karakter-karakter dalam dongeng yang sering diceritakan terkadang memiliki kemampuan khusus (supranatural), seperti Cindelaras yang memiliki ayam sakti, Keong Mas yang bisa berubah bentuk, Lutung Kasarung yang memiliki kesaktian, dan sebagainya. Umumnya dongeng mengisahkan Dewa, raja dan ratu, pangeran, dan lainnya. Dongeng yang ada di nusantara banyak bercerita peristiwa di zaman lampau, sehingga didominasi cerita kerajaan dan melalui akulturasi Hindu-Buddha yang percaya Dewa-Dewi. Karena disampaikan dengan lisan, dongeng tidak diketahui siapa penciptanya. Pada mulanya dongeng muncul dari opini masyarakat dalam suatu kelompok di wilayah tertentu untuk menghibur dan memuaskan angan-angan (Setiawan, 2004: 399). 
Cerita atau dongeng rakyat adalah cerita khayal yang merupakan campuran antara kenyataan dan alam gaib yang penuh keanehan dan tidak terikat pada masalah cerita. memiliki susunan kalimat yang sederhana. pada prolog dan epilog bersifat klise. dongeng rakyat dikisahkan secara lisan turun temurun dan tidak dikenal siapa pengarangnya. banyak teori yang diajukan mengenai asal usul dongeng rakyat, antara lain yang bersifat mitologis, alegoris, dan psychoanalysis.

Dongeng rakyat mitologis misalnya legenda-legenda seperti terjadinya Rawa Pening di Jawa Tengah, terjadinya Danau Situ Bagendit di Jawa Barat, atau seperti Banyuwangi yang ada di Jawa Timur, dan banyak lagi lainnya. Setelah ada beberapa sastrawan yang mengumpulkan dongeng rakyat dan membukukannya misalnya dua bersaudara Grimm dari Jerman muncullah beberapa sastrawan yang tertarik untuk mengarang dongeng, misalnya HC Andersen dari Denmark yang terkenal dengan dongeng satiris dan penuh ajaran moral (Setiawan, 2004: 400).

\section{Cerita Rakyat Cinderlaras}

Cerita tentang Cindelaras berkembang di tengah masyarakat Jawa Timur. Disampaikan secara lisan, turun-temurun, bersifat tradisional, memiliki banyak versi, dan tidak diketahui siapa yang pertama kali membuatnya. Cerita ini berkisah di sebuah kerajaan bernama Jenggala di Jawa Timur. Berdasarkan catatan sejarah, kerajaan Jenggala adalah sebuah kerajaan yang berdiri sekitar tahun 1042, dan berakhir sekitar tahun 1130-an. Diperkirakan lokasi pusat kerajaan ini sekarang berada di wilayah Kabupaten Sidoarjo, Jawa Timur (Komandoko, 2013: 33).

Nama Tokoh dalam Cerita Cindelaras Sebelum mengetahui jalan ceritanya, berikut ini nama-nama tokoh dalam cerita Cindelaras.

1. Cindelaras memiliki sifat berbakti kepada orangtua, baik hati, percaya diri, cerdas dan pantang menyerah.

2. Permaisuri memiliki sifat baik hati, cerdas, dan penyabar.

3. Selir memiliki sifat tidak puas dengan kekdudukannya, selalu iri pada permaisuri dan pendengki.

4. Raden Putra raja kerajaan Jenggala yang memiliki sifat baik, tegas, mudah terhasut.

5. Tabib Istana memiliki sifat jahat, tukang fitnah, cinta duniawi. 
6. Ayam Jantan milik Cindelaras memiliki sifat tangguh dan pemberani (Komandoko, 2013: 36).

Kerajaan itu dipimpin oleh raja bernama Raden Putra. Singkat cerita Raden Putra sangat suka mengadu ayam. Raden Putra karena seorang raja memiliki permaisuri dan beberapa orang selir. Tetapi salah satu selirnya iri terhadap permaisuri karena telah mengandung dan takut kekuasaan kerajaan akan dilimpahkan semua pada calon anak permaisuri. Sang selir pun berencana untuk menjebak permaisuri dengan berpura-pura baik. Kemudian di saat jam makan istana si selir menabur racun kepada makanan yang akan dihidangkan kepada raja. Kemudian dengan bantuan tabib istana, sang selir mengkambinghitamkan permaisuri, sebagai pelaku yang meracuni raja.

Raden Putra sangat marah dan murka mendengar ucapan sang selir. Raja memerintahkan prajurit membunuh permaisuri di hutan. Tetapi, sesampainya di hutan prajurit baik ini tidak tega menyakiti permaisuri apalagi membunuhnya.. prajurit ttersebut menangkap seekor rusa dan membawa jantungnya kepada raja sebagai bukti. Pada cerita lain prajurit itu mencari kelinci dan menggoroknya, kemudia darah kelinci tersebut sebgai bukti kepada raja.

Permaisuri melahirkan bayi laki-laki yang kemudian diberi nama Cindelaras. Cindelaras kecil sangat suka bermain di hutan. Suatu hari ia menemukan sebutir telur ayam. Setelah dirawat dengan baik akhirnya menetaslah ayam jago Cindelaras. Setelah ayam tersebut cukup besar mulailah Cindelaras menemukan hobbynya dengan mengadu ayam yang dimilikinya. Buah jatuh tidak jauh dari pohonnya, perumpamaan itu mewakili Cindelaras dengan raja yang sama-sama suka mengadu ayam. Cindelaras pun berkelana dari satu tempat ke tempat lain untuk mengadu ayam, suatu keajaiban yang terjadi karena ayam jago itu tidak pernah kalah barang satu kalipun.

Cindelaras dan ayamnya mulai dikenal oleh orang banyak. Hingga suatu saat Raja mengundang Cindelaras ke kerajaan. Sesampainya di sana Raja terheran bagaimana mungkin anak yang tinggal di hutan memiliki perilaku seperti anak bangsawan. Karena sama sama suka mengadu ayam raja meminta Cindelaras mengadu ayam yang kata ornag tidak pernah kalah itu dengan ayam jagoan milik raja. Itu semua akan dipenuhi oleh Cindelaras tetapi dengan syarat bila ayam Cindelaras menang raja harus membagi kekuasaan yang dimilikinya kepada Cindelaras (Komandoko, 2013: 34).

Setelah di mulai pertarungan dari dua ayam jago tersebut tidak lama ayam raja kalah. Semua orang terkejut. Mereka lebih heran lagi ketika ayam Cindelaras berkokok. Bunyinya, 'Kukuruuyuuuk...! Akulah ayam jago Cindelaras, yang hidup di hutan, tapi ia anak Raden 
Putra!" Ayam itu lantas berkokok. Raja sangat terkejut. Ia kemudian memanggil Cindelaras mendekat. "Siapa namamu? Di mana rumahmu?" tanya raja. "Nama saya Cindelaras, yang mulia. Saya tinggal bersama ibu di hutan" "Siapa nama ibumu?" Cindelaras menyebutkan nama ibunya hingga membuat raja kaget dan terperanjat.

Raja menyuruh prajurit untuk menjemput ibu Cindelaras di rumahnya yang ada dalam hutan. Di sana raja melihat seorang wanita dan langsung mengenalinya sebagai permaisuri yang dulu hendak dibunuhnya. Permaisuri menceritakan bahwa ia difitnah dan ia melahirkan Cindelaras. Raja sangat menyesal karena ia dulu terburu nafsu. Ia mengajak permaisuri dan Cindelaras kembali ke istana. Raja mengukuhkan kembali kedudukan permaisuri dan menghukum selir yang jahat itu. Setelah raja meninggal, Cindelaras menggantikannya menjadi raja. Cindelaras memerintah dengan adil dan bijaksana (http://www.resourcefulparenting.com/index.php?option=com_content $\&$ view $=$ article $\&$ id $=177$ : kisah-cinde-larascerita-rakyat-dari-jawa-timur\&catid $=36$ :cerita-anak $\&$ Itemid $=60$ ).

Kisah ini memeliki banyak versi, dan diatara versi tersebut versi inilah yang paling masyhur di kalangan buku-buku dongeng. Meskipun sudah bisa ditebak jalan cerita (alur) dari kisah Cindelaras ini, tetapi banyak pelajaran yang bisa dipetik dari kebaikan permaisuri dan kegigihan Cindelaras.

\section{Kepercayaan diri dengan nilai-nilai pada cerita rakyat Cindelaras}

Untuk membentuk suatu karakter sebagai generasi millenials yang unggul, maka perlu persiapan yang matang. Karena itu akan mempengaruhi tumbuh kembang anak di tahap-tahap selanjutnya. Dari masa kecil atau baru mengenal sesuatu hingga pada masa produktivitas di saat dewasa. Salah satu tujuan dari pendidikan yang disampaikan melalui dongeng agar seorang anak memiliki kekuatan spiritual, pengendalian diri, kepribadian, kecerdasan, kepercayaan diri, akhlak mulia, dan keterampilan atau keahlian yang dibutuhkan. Ini semua agar anak dapat mengikuti ritme terhadap sesuatu yang akan diberikan baik dalam faktor sosial maupun pendidikan.

Pada penelitian yang dilakukan oleh Ida Ayu dkk (2004), dalam jurnal yang berjudul penerapan penggunaan media permainan fantasi dan imajinasi kreatif untuk meningkatkan kemampuan otak kanan dan mengembangkan kemampuan berbahasa, menunjukkan bahwa kemampuan kreativitas anak Indonesia dinilai kurang. ini terbukti ketika anak diberikan suatu tugas dengan menyusun Suatu bentuk potongan-potongan kayu lidi agar dibentuk menjadi di suatu objek baru, mereka kesusahan. 
Kreativitas erat keterkaitannya dengan imajinasi. Sehingga apabila imajinasi anak tidak sesuai standar anak lainnya, maka kemampuannya dalam mengekspresikan ide-ide orisinilnya akan terhambat. Itu pula sebaliknya, suatu imajinasi yang tinggi akan menghasilkan kreativitas dan karya-karya yang bisa dikembangkan lagi dan lagi. Imajinasi yang terbentuk pada anak, biasanya didapatidari kebebasan mereka dalam melakukan banyak hal. Maka peran orang di sekitarnya adalah mengarahkan tanpa melarang.

Terdapat suatu penelitian lain yang menjelaskan ketika mendengarkan suatu cerita rakyat tentang kisah peri atau raksasa yang jahat dalam cerita fantasi terkadang anak kurang memperhatikan, padahal kegiatan ini bertujuan untuk mengembangkan imajinasi dan kemampuan berbahasa anak di samping mengajarkan bahwa ada beberapa nilai moral yang bisa dipetik dari cerita atau kisah yang mereka dengarkan. Dari uraian yang disebutkan maka peranan guru menjadi sangat urgent. Guru diwajibkan agar mampu membuat anak didik mereka selayaknya di usia mereka dengan dorongan input input yang telah guru persiapkan seperti dongeng,tarian, lagu, permainan, dan kegiatan motorik lainnya (Widhiani, 2014: 10).

Salah satu potensi dari seorang anak adalah rasa percaya diri luar biasa dan itu bisa dikembangkan dengan aktivitas bermain sambil belajar. Banyak pakar seperti Tivigotsky yang meyakini dengan bermain dan berdongeng akan mengarahkan perkembangan seorang anak. dalam suatu cerita semisal, anak-anak anak mampu mempraktekkan keterampilan dan keahlian yang diperoleh dan mengambil peran-peran sosial baru.

Anak dilatih mencoba tugas baru yang lebih menantang, serta mencari suatu solusi pada masalah yang lebih kompleks. Itu memungkinkan mereka mengenal peran baik dan buruk yang menjadi norma suatu wilayah. Selain itu dengan berdongeng akan mendukung kognitif dengan menerapkan fungsi penting dalam perkembangan fisik, emosi, dan sosial anak. Dalam dunianya, anak mengekspresikan dan mengemukakan ide-ide serta perasaan mereka dengan cara yang mereka bisa. oleh karena itu, orang disekitar mereka merupakan peranan yang esensial dalam perkembangan psikomotorik anak (Priyanto, 2014: 42).

Adapun beberapa nilai-nilai moral yang bisa diambil agar membentuk pribadi anak yang percaya diri dari cerita Cindelaras:

1. Fitnah memiliki dampak atau efek yang luar biasa. Salah satunya bisa menjadi cobaan dan ujian bagi korbannya. Dalam kalimat yang lain dikatakan bahwa fitnah lebih kejam daripada pembunuhan (Latif, 2015: 87).

2. Becik ketitik ala ketoro, dalam istilah bahasa Jawa ini berarti kebaikan akan terlihat dan keburukan akan ketahuan. Suatu saat kebaikan itu akan terungkap, 
entah dari manapun jalannya. Dan kejelekan pun juga akan mendapatkan ganjarannya yang setimpal. Jika tidak dibalas sekarang di dunia, akan dibalas kelak nanti.

3. Manusia memiliki sifat iri dan dengki. Bagaimanapun baiknya seseorang selalu ada orang yang akan memusuhi (Haekal, 2007: 301)

4. Tidak menyerah. Terkadang banyak hal buruk yang menimpa, terkadang takdir tidak selalu berjalan mulus. Tetapi dengan berusaha dan berdoa semua masalahmasalah tersebut akan teratasi.

5. Sabar menghadapi cobaan. Satu kata yang biasa didengar tapi sangat susah diterapkan. Pengendalian emosi itu sangat diperlukan, agar tidak terjadi hal-hal fatal yang dilakukan (Subandi, 2011: 220).

6. Tidak mudah percaya. Dalam filsafat ilmu disebutkan bahwa ketika mendapatkan informasi atau pengetahuan baru harus ditelusuri dulu tentang kebenarannya (Endraswara, 2018: 37).

7. Berbohong tidak selalu buruk. Kebohongan untuk menyelamatkan seseorang yang mendapati perlakuan tidak adil bisa jadi menjadi kebohongan yang baik.

8. Tawakkal. Memang pada cerita Cindelaras tidak dimasukkan peran Tuhan atau Dewa dalam jalan cerita ini. Tetapi sebagai Muslim yang baik, harus senantiasa berpikir bahwa semua yang ada di dunia ini telah diatur oleh Allah Swt Tuhan semesta alam.

9. Tidak rendah diri. Dari apapun latarbelakang seseorang tidak boleh terbersit dari hati orang tersebut merasa rendah dibandingkan yang lain. Jikalau Cindelaras tidak meerima tantangan Raja, maka belum tentu dia dan ibunya bisa menguak kebenaran yang sempat tertutupi.

10. Setiap perbuatan akan mendapatkan ganjarannya. "Apa yang ditanam itulah yang akan dituai". Seperti dalam Al-Kitab (Arivia Amsal, 11:18) itulah peribahasa yang cukup menjadi pengingat akan menjaga diri dari perbuatan buruk dan selalu berupaya melakukan kebaikan.

11. Menghormati dan menyayangi orang tua. Sehebat apapun orang, sejaya apapun dia, setinggi apapun kariernya, sangat mudah bagi Allah untuk menjatuhkan kita pada serendah-rendahnya derajat, apabila yang bersangkutan sampai menyakiti hati ibu dan bapaknya (Kurniawati, 2013).

Karakteristik/ciri-ciri lain dari rasa percaya diri yaitu: 
1. Percaya akan kemampuan yang dimiliki tanpa menggantungkan bantuan dari orang lain,

2. Mencintai diri sendiri dan berani melangkah atas usahanya.

3. Memiliki emosi yang stabil dan tenang dalam menghadapi rintangan.

4. Memiliki kemauan yang tinggi

5. Tidak mudah menyerah

6. Berani mengambil resiko

7. Tidak menghiraukan tanggapan negatif orang lain

Dengan mengetahui pentingnya membangun rasa percaya diri, keluarga dan guru mampu menciptakan atmosfir yang ramah pada anak. Sehingga anak mempunyai rasa percaya diri yang tinggi, tujuannya adalah anak tidak akan takut mencoba berkreasi terhadap hal baru. Menerut Anggraeni anak dengan rasa percaya diri yang rendah akan sangat memerlukan dorongan dan dukungan terus menerus (Anggreni, 2009: 54). Itulah beberapa beberapa saran yang bisa diterapkan untuk membangun rasa percaya diri anak.

Metode dongeng sebagai stimulasi berperan dalam meningkatkan perkembangan kecerdasan moral anak. Selain itu, tingkat kecerdasan moral setelah mendapatkan penyampaian nilai moral dengan metode dongeng lebih tinggi dibandingkan tingkat kecerdasan moral sebelum mendapatkan penyampaian nilai moral melalui metode dongeng (Ahyani, 2010: 31).

\section{Dukungan orangtua dalam meningkatkan kepercayaan diri}

Hurlock menyatakan bahwa seseorang memiliki kepercayaan diri yang tinggi jika si anak mampu membuat pernyataan pernyataan positif mengenai dirinya, menghargai diri sendiri, serta mampu mengejar harapan-harapan yang kemungkinan membuatnya berhasil akan hal tersebut. Anak yang percaya diri bisa dilihat dari sikap tenang mereka dalam mengontrol diri dan emosi. Itu juga tampak dengan tidak Mudah terpengaruh nya mereka oleh situasi yang kebanyakan orang nilainya sebagai hal yang negatif.

Menurut Lindelfeld seseorang yang mampu mengontrol dan mengendalikan emosi dengan baik cenderung lebih percaya diri karena tidak khawatir akan lepas kendali saat menghadapi tantangan yang beresiko. Orang yang percaya diri biasa mengatasi rasa khawatir, takut, dan cemas serta mampu mengatasi konfrontasi cara efektif dan konstruktif. Di sisi lain pola asuh orang tua sangat berpengaruh terhadap tumbuh kembang anak, khususnya pada pola asuh demokrasi orang tua. Orang tua tidak otoriter dalam memaksakan kehendaknya, 
biasanya orang tua pada tipe ini, termasuk kepada orang tua dengan SDM rendah maupun yang kurang terbuka (Gael, 1997: 25).

Kebutuhan anak dalam mengisi ruang memori mereka sebaiknya dilakukan gaya pengasuhan yang berlandaskan kasih sayang, keterbukaan, kedisiplinan, kemandirian, dan tanggung jawab. Jika seorang anak melakukan pelanggaran peringatan dan hukuman secukupnya dapat menanamkan budi pekerti dan moral. Jika seorang anak berprestasi hadiah kecil seperti pujian dibutuhkan untuk meningkatkan semangat dan motivasi mereka. Salahnya pendidikan kan yang diasumsikan sebagai pendidikan yang tidak demokratis dan terbuka terhadap anak mengakibatkan mereka kesulitan dalam hubungan sosial dan akan timbulnya perilaku kompleks yang cenderung negatif atau kenakalan-kenakalan sebagai kompensasi dari kurangnya pendidikan yang yang diberikan oleh orang tua dengan benar (Rahman, 2012: 79).

Kemandirian dan percaya diri dari seorang anak ditingkatkan melalui dalam suatu proses kehidupannya. Anak yang diberi kesempatan untuk membantu tugas orang disekitarnya meskipun tidak maksimal, mereka akan merasa berhasil dan dihargai. maka, rasa percaya diri akan bertambah, ada kepuasan diri dan itu membentuk kemandirian anak lebih berkembang (Anggreni, 2017: 7).

\section{PENUTUP}

\section{Simpulan}

Dari uraian mulai dari pendahuluan, kajian putaka, dan pembahasan terdapat beberapa poin yang bisa disimpulkan, diantaranya: Cerita rakyat yang diambil dalam penelitian ini adalah Cindelaras, suatu kisah dari kerajaan Jenggala yang konon ada di Sidoarjo. Alur kisah ini menceritakan kisah Cindelaras, nama seorang pemuda yang terusir dikarenakan fitnah selir sebab iri dan ingin menguasai kerajaan. Mengambil nilai-nilai yang ada pada cerita akan meningkatkan percaya diri dongeng atau cerita rakyat karena itu akan merangsang seorang anak untuk mengerti hal baik dan buruk. Membangun rasa percaya diri, seseorang anak yang mempunyai rasa percaya diri yang tinggi dan tidak akan takut mencoba hal-hal yang baru akan berdampak positif pada tahap selanjutnya, baik di masa sekolah hingga di masa kerja. Penggunaan cerita rakyat atau dongeng sebagai penanaman rasa percaya diri pada anak juga memiliki nilai lebih. Karena secara tidak langsung memunculkan kembali cerita-cerita autentik kearifan lokal Indonesia yang sempat terpendam, dengan cerita- cerita asing yang masuk di Indonesia. 


\section{DAFTAR PUSTAKA}

Ahyani, Latifah Nur. 2010. METODE DONGENG DALAM MENINGKATKAN PERKEMBANGAN KECERDASAN MORAL ANAK USIA PRASEKOLAH. Jurnal Psikologi Universitas Muria Kudus Vol 1, No 1.

Aprianti, Rahayu. 2013. Menumbuhkan Kepercayaan Diri Anak Melalui Kegiatan Bercerita. Jakarta: Permata Puri Media.

Alkitab. 2004. Jakarta: Lembaga Alkitab Indonesia. Arivia Amsal

Anggreni, Ayu Made. 2017. PENERAPANBERMAIN UNTUK MEMBANGUN RASA PERCAYA DIRI ANAK USIA DINI, Journal OfEarly Childhood and Inclusive Education, Vol 1, No 1.

Anggreni, Ayu Made. 2009. Skripsi "Pengaruh Penggunaan Sentra Balok Terhadap Rasa Percaya Diri

Anak Kelompok Usia 4-5 Tahun". Surabaya: UNESA Ardini, Puspa. 2012. PENGARUH DONGENG DAN KOMUNIKASI TERHADAP PERKEMBANGAN MORAL ANAK USIA 7-8 TAHUN. Jurnal pendidikan Anak Vol 1, No 1.

Azzah, Zaimul. 2016. Melestarikan Budaya Melalui Lomba Dongeng Bertemakan Nilai Kejujuran Pembukaan Lomba Dongeng BPNB DIY Oleh Kepala BPNB DIY (Zaimul Azzah) tanggal 13 September 2016.

Cooper, Hilary. 2014. Writing History 7-11: Historical writing in different genres. Cumbria: Routledge.

D, Carr. 1991. Time, Narrative, History. Bloomington: Indiana University Press.

Dudung. 2015. Deskripsi, Narasi Dan Eksposisi Menurut Ahli Sastra. Diambil dari: http://www.dosenpendidikan.com/pengertian-deskripsi-narasi-dan-eksposisimenurut-ahlisastra/.

Endraswara, Filsafat Ilmu karangan Prof. Dr. Suwardi Caps Publishing 2018.

Folklor, https:/id.wikipedia.org/wiki/Folklor diakses tanggal 23 Mei 2020.

Gael, Lindenfield. 1997. Mendidik Anak Agar Percaya Diri. Jakarta: Arcan.

Haekal, Husein. 2007. Muhammad. Diterjemahkan Ali Uda. Jakarta. Litera Nusa

Habsari, Zakia. 2017. DONGENG SEBAGAI PEMBENTUK KARAKTER ANAK. BIBLIOTIKA Jurnal Kajian Perpustakaan dan Informasi Vol 1, No 1.

Idrus, Fahmi. 2007. Kamus Lengkap Bahasa Indonesia. Surabaya: Grisenda press. 
Jananti, N. Tarsis Tarmudji. 2014. PENGARUH KEPERCAYAAN DIRI, BUDAYA LOKAL DAN PENDIDIKAN AGAMA TERHADAP HASIL BELAJAR MATA PELAJARAN EKONOMI SISWA KELAS XI IPS SMA NEGERI 1 DEMAK TAHUN AJARAN 2013/2014. Economic Education Analysis Journal, Vol 3 No 2.

Khotimah, Apriana Khusnul dan Nurul Quwwatun. "MENGEMBANGKAN KEPERCAYAAN DIRI ANAK MELALUI KOMUNIKASI EKSPRESIF PADA PEMBELAJARAN DI KELAS ANAK USIA DINI", Prosiding Seminar Nasional Pendidikan 7 November 2015.

Komandoko, Gamal. 2013. Koleksi Terbaik 100 plus Dongeng Rakyat Nusantara. Jakarta: PT.Buku Seru.

Kusumo, Priyono. 2006. Terampil Mendongeng. Jakarta : Grasindo.

Kurniawati, N. dkk. 2013. Seminar Nasional Psikologi UMS 1 Juni.

Latif, umar. 2015. KONSEP FITNAH MENURUT AL-QURAN. jurnal.ar-raniry Vol 21, No 1.

Nurhaidah „ M. Insya Musa. 2015. DAMPAK PENGARUH GLOBALISASI BAGI KEHIDUPAN BANGSA INDONESIA Jurnal Pesona Dasar, Vol. 3 No. 3.

Priyanto, Aris. 2014. PENGEMBANGAN KREATIVITAS PADA ANAK USIA DINI MELALUI AKTIVITAS BERMAIN, Jurnal Ilmiah Guru, Vol 1 No 2.

Rahman, Fathur dan Herlan Pratikto. 2012. "KEPERCAYAAN DIRI, KEMATANGAN EMOSI, POLA ASUH ORANG TUA DEMOKRATIS DAN KENAKALAN REMAJA". Persona Jurnal Psikologi Indonesia, ,Vol 1, No 2.

Sri, Suneki. 2012. Dampak Globalisasi Terhadap Eksistensi Budaya Daerah. _ Jurnal ilmiah CIVIS, Vol 2, No 1.

Setiawan, Boenjamin dkk. 2004. Ensiklopedi Nasional Indonesia (Jilid 2). Jakarta: PT Delta Pamungkas..

Setiawan, Boenjamin dkk. 2004. Ensiklopedi Nasional Indonesia (jilid 5). Jakarta: PT Delta Pamungkas.

Subandi, M.A. (2011) Sabar: Sebuah Konsep Psikologi. Jurnal Psikologi Vol 38 No 2.

Suparno, Paul. 2012. PENGEMBANGAN KARAKTER UNTUK ANAK ZAMAN SEKARANG. Seminar Pendidikan yang diselenggarakan oleh Unit PPL FKIP, USD, tanggal 28 November 2012.

Widhiani, Ida Ayu Sri. A.A.I.N Marhaeni. I Nyoman Dantes. 2014. PENERAPAN PENGGUNAAN MEDIA PERMAINAN FANTASI DAN IMAJINASI KREATIF UNTUK MENINGKATKAN 


\section{KEMAMPUAN OTAK KANAN DAN MENGEMBANGKAN KEMAMPUAN}

BERBAHASA, e-Journal Program Pascasarjana Universitas Pendidikan Ganesha Program Studi Pendidikan Dasar Vol 4.

$\begin{array}{llll}\text { Saputra, Sandi. Hilangnya } & \text { Budaya }\end{array}$ (https://www.kompasiana.com/3185/5c000e9643322f383978c383/hilangnya-budayaindonesia).

http://www.resourceful-parenting.com/index.php?option=com_content\&view= article\&id=177:kisahcinde-laras-cerita-rakyat-dari-jawa-timur\&catid=36: cerita-anak $\&$ Itemid $=60$ 